\title{
A fully-automated statistical method for characterization of flow artifact presence in cardiac MRI
}

\author{
Sotirios A Tsaftaris ${ }^{1 *}$, Xiangzhi Zhou ${ }^{2}$, Rohan Dharmakumar ${ }^{2}$ \\ From 2011 SCMR/Euro CMR Joint Scientific Sessions \\ Nice, France. 3-6 February 2011
}

\section{Introduction}

Flow artifacts in MR images can appear as ghosts within and outside the body cavity. Current approaches for optimizing sequences for suppressing such artifacts rely on expert scoring or on semi-automated methods for evaluation.

\section{Purpose}

To test a fully-automated statistical image-processing method that can quantify the presence of flow artifacts. The method was evaluated against expert scoring in the setting of cine blood-oxygen-level-dependent (BOLD) MRI with different SSFP imaging strategies.

\section{Methods}

\section{Imaging studies}

Six healthy dogs were studied in a Siemens $1.5 \mathrm{~T}$ scanner using three breath-held 2D SSFP cine sequences (Table 1) in the basal position where flow artifacts are most pronounced. Shared scan parameters: spatial_resolution $=1.2 \times 1.2 \times 5 \mathrm{~mm} 3$, flip_angle $=70^{\circ}$, temporal_resolution $=10-12 \mathrm{~ms}$, no parallel imaging.

Table 1 2D cine SSFP Imaging sequences and parameters used. Shared parameters in text

\begin{tabular}{llllll}
\hline Sequence & $\begin{array}{l}\text { BOLD } \\
\text { sensitivity }\end{array}$ & $\begin{array}{l}\text { Flow } \\
\text { artifacts }\end{array}$ & TR & $\begin{array}{l}\text { BW } \\
\text { Flow } \\
\text { compensation }\end{array}$ \\
\hline A & negligible & minimal & 3.5 & 930 & no \\
B & optimal & significant & 6.2 & 239 & no \\
C & optimal & reduced & 6.2 & 930 & yes \\
\hline
\end{tabular}

${ }^{1}$ Northwestern University, Evanston, IL, USA

Full list of author information is available at the end of the article

\section{Image processing}

Each cine stack $\mathrm{I}(\mathrm{t})$ ( $\mathrm{t}$ denotes trigger time) was loaded in Matlab and the per-pixel mean $\left(\mathrm{I}_{\mathrm{A}}\right)$ and variance $\left(\mathrm{I}_{\mathrm{V}}\right)$ were found across $t$. Initialized with a rectangle the size of $\mathrm{I}_{\mathrm{A}}$, a contour was evolved, using a level-set approach, until it converged to the body-air interface, providing a binary mask $M\left(\mathrm{M}=1\right.$ for air). Image $\mathrm{I}_{\mathrm{R}}=\mathrm{I}_{\mathrm{V}} /\left(\mathrm{I}_{\mathrm{A}}\right)^{2}$ (pixelwise division) was calculated and all values of $I_{R}$ in air $(M=1)$ were collected to estimate the excess kurtosis $(\gamma)$ of their distribution $H$. The metric $\mathrm{Q}_{\mathrm{K}}=\gamma$ was used to quantify the presence of flow artifacts.

\section{Data analysis}

Three expert reviewers, blinded to sequence type, scored 16 studies for the presence of ghosts [1(least) to 5 (most)]. ANOVA was used to test for differences in scores/metric among sequences. $\mathrm{Q}_{\mathrm{K}}$ was correlated with the reviewers' median choice $\left(\mathrm{Q}_{\mathrm{H}}\right)$ to assess agreement.

\section{Results}

Fig. 1 shows a representative case from a study acquired with sequence B. Fig. 2 shows bar plots of $Q_{K}$ values and scores $\left(\mathrm{Q}_{\mathrm{H}}\right)$ for each imaging sequence. Correlation coefficient between $\mathrm{Q}_{\mathrm{K}}$ and $\mathrm{Q}_{\mathrm{H}}$ was $0.7\left(\mathrm{R}^{2}=0.49\right.$; $\mathrm{P}<0.01)$.

\section{Conclusions}

Statistical comparisons of $\mathrm{Q}_{\mathrm{K}}$ scores identified a difference in the presence of ghost artifacts among the three sequences in full agreement with expert findings. This indicates that this kurtosis-based method can assess the variability of artifact presence in a stack without the need to process each image separately. In contrast to other methods, the proposed approach uses high order statistics (kurtosis) of background pixels to estimate 

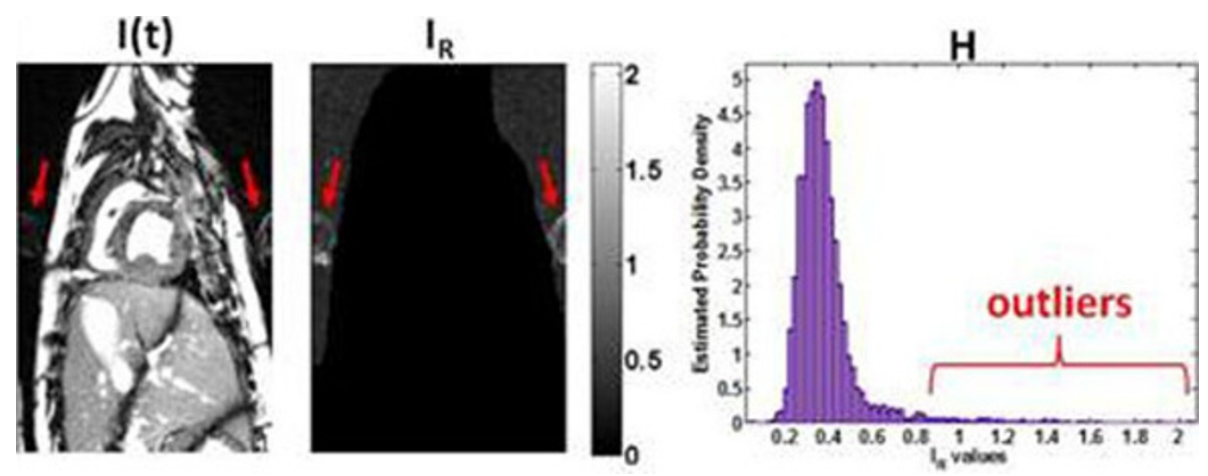

Figure 1 Images from a canine study acquired with sequence B, showing the presence of artifacts and steps of the proposed method. Left: a systolic image ( $22^{\text {nd }}$ frame in 55 total frames) of the study, showing optimal BOLD sensitivity and significant flow artifacts. Middle: The $I_{R}$ image as defined in the methods indicating that artifact information is retained (only pixels in air are shown as found by the level-set segmentation): the arrows point to artifacts. Right: The distribution $(H)$ of the $I_{R}$ values in air: bracket indicates $I_{R}$ values from ghost artifact regions (see arrows in middle image) that act as outliers. Due to the presence of these outliers the excess kurtosis for this stack was $y=Q_{k}=21$.

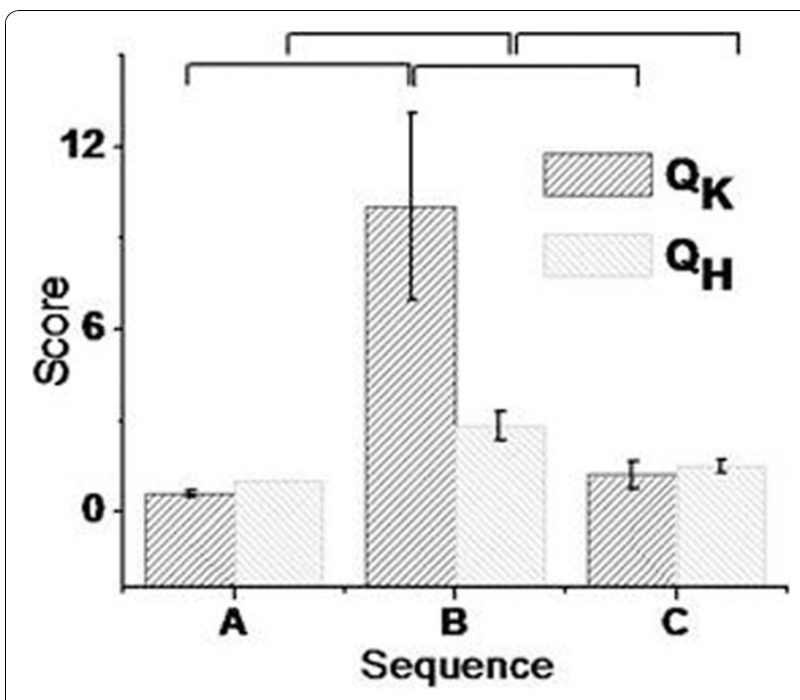

Figure 2 Bar plots (mean \pm standard error) for $Q_{K}$ (derived using the kurtosis-based method) and $\mathrm{Q}_{H}$ (the experts median choice per study) grouped by sequence type. Intervals on top indicate statistical significance of individual comparisons $(P<0.05)$. KruskalWallis ANOVA with Tukey-Post-Hoc analysis of $Q_{k}$ and expert scores identified a difference in the presence of ghost artifacts in images acquired with sequences $A$ and $B$ or $B$ and $C$.

ghost presence and is robust against (coil) bias due to the division with per-pixel mean image $\mathrm{I}_{\mathrm{A}}$. Although further studies are needed, the proposed approach may be useful in readily assessing image quality in a clinical/ research setting in an unbiased and fully-automated manner.

\section{Author details}

${ }^{1}$ Northwestern University, Evanston, IL, USA. ${ }^{2}$ Northwestern University, Chicago, IL, USA.
Published: 2 February 2011

doi:10.1186/1532-429X-13-S1-P45

Cite this article as: Tsaftaris et al:: A fully-automated statistical method for characterization of flow artifact presence in cardiac MRI. Journal of Cardiovascular Magnetic Resonance 2011 13(Suppl 1):P45.

\section{Submit your next manuscript to BioMed Central and take full advantage of:}

- Convenient online submission

- Thorough peer review

- No space constraints or color figure charges

- Immediate publication on acceptance

- Inclusion in PubMed, CAS, Scopus and Google Scholar

- Research which is freely available for redistribution 